\title{
(2) OPEN ACCESS \\ Looking back on the history of patient safety: an opportunity to reflect and ponder future challenges
}

\author{
Gordon Schiff $\left(\mathbb{1},{ }^{1}\right.$ Kaveh G Shojania (i) ${ }^{2}$
}

${ }^{1}$ General Medicine, Brigham and Women's Hospital Department of Medicine, Boston, Massachusetts, USA ${ }^{2}$ Department of Medicine and the Centre for Quality Improvement and Patient Safety, University of Toronto, Sunnybrook Health Sciences Centre, Toronto, Ontario, Canada

\section{Correspondence to} Dr Gordon Schiff, General Medicine, Brigham and Women's Hospital Department of Medicine, Boston, MA 02120, USA; gschiff@partners.org

Received 25 August 2021 Accepted 27 September 2021

\section{Check for updates}

(c) Author(s) (or their employer(s)) 2021. Re-use permitted under CC BY-NC. No commercial re-use. See rights and permissions. Published by BMJ.

To cite: Schiff G, Shojania KG. BMJ Qual Saf Epub ahead of print: [please include Day Month Year]. doi:10.1136/ bmjqs-2021-014163
The publication of To Err is Human ${ }^{1}$ by the US Institute of Medicine (IOM) helped launch not just the field of patient safety but the broader interest in healthcare quality. The report's estimates of 44000-98 000 annual deaths from medical error in US hospitals-eyecatchingly equated to a jumbo jet crashing every day and a half-captured headlines and widespread attention. The IOM (now the National Academy of Medicine, NAM) followed up this success with Crossing the Quality Chasm, ${ }^{2}$ which notably defined quality in terms of six distinct dimensions, including not just safety, but also effectiveness, patient centredness, efficiency, timeliness and equity.

Many might have feared that the interest generated by these two reports would represent passing fads rather than enduring fields. Thankfully, that has not occurred. Patient safety and broader quality improvement efforts remain active areas of research and operational activities in healthcare organisations around the world. In addition, some funding agencies focus on healthcare quality, as do an increasing number of journals, such as BMJ Quality and Safety, and many public interest advocacy groups have been spawned.

It thus feels fitting that a new book, Making Healthcare Safe: The Story of the Patient Safety Movement, ${ }^{3}$ should recount the birth and subsequent development of patient safety as a field. The author, Lucian Leape, played a leading role in launching the field-not just as one of the authors of To Err is Human, but also through numerous prior and subsequent contributions. Leape helped lead the seminal Harvard Medical Practice Study ${ }^{4}$ - one of the two large studies that generated the widely quoted estimates of deaths due to medical error. A few years later, Leape's groundbreaking article on Error in Medicine ${ }^{5}$ outlined many ideas that remain paradigmatic. Fast forward a quarter century and we now have this firsthand account of the major early and more recent milestones in patient safety. While not a systematic literature review, we nonetheless learn about the people and events that shaped the patient safety landscape, benefiting from the rich paper trail of publications, white papers and recommendations, many of which Leape had a hand in organising and writing. $\mathrm{He}$ weaves together the threads of the various key projects and initiatives, and most importantly offers his critical analysis of their successes and failures. True to one of the key transformative themes of patient safety-candour-Leape freely shares his opinions of the actors and controversies, and readers may especially enjoy the anecdotes and backstories behind this history.

The book is long (436 pages) but includes much that will interest both veterans and newcomers to the field. It is divided into four sections: (1) beginnings, describing the research and theory that defined patient safety and early initiatives; (2) institutional responses, telling the stories of the efforts of major organisations, coalitions, governmental and regulatory agencies, (3) in-depth analyses of four key cross-cutting issueswork duty hours, disclosure and apology, physician competence, building respectful culture; and (4) forging a future based on a culture of safety.

Because Leape played parts in so many of the events and initiatives, the distinction between history and memoir often blurs. To his credit and because he helped shape so many of the major safety initiatives over the past two decades, the book is quite comprehensive in its coverage. The scant attention to efforts to characterise 
and reduce diagnostic errors probably represents the most notable omission. A century-long literature exists on clinically important missed diagnoses detected at autopsy, ${ }^{67}$ with renewed attention to improving diagnostic safety over the past decade including annual international conferences on Diagnostic Error in Medicine, a NAM Report on Improving Diagnosis and multiple research studies. ${ }^{8-11}$ Diagnostic errors, arguably the most frequent error reported by patients and most common cause of malpractice claims, ${ }^{12}{ }^{13}$ represent not only an omission from the book, but an oversight of the early patient safety movement on which this personal history is based.

Two topics Leape does cover are worth calling out. One relates to surgical safety, an area to which, as a paediatric surgeon, Leape feels a deep connection. While he extols the initial successful efforts around the so-called surgical checklist, he admits it fell short when advocates attempted spread it to hospitals and surgeons less committed to the culture and practices it embodies. Leape candidly confesses that, in his years practising surgery, it never occurred to him that teamwork was key to better outcomes, assuming as many surgeons do, that they constitute 'captains of the ship' and their skill and authority were what most mattered. Leape writes he was therefore not surprised to see the resistance to change. He admits that despite initial optimism, the degree to which checklists have improved surgical safety remains unclear. ${ }^{14}$

The other topic that Leape takes on-controversially and bravely-concerns the competence of clinicians. The most important initial insight of the patient safety movement was that errors are largely the result of bad systems, not bad people. However, Leape does not rest on the more superficial and simplistic application of this principle. He recognised that incompetent individuals in themselves have their roots in system problems and explores ways of addressing them. ${ }^{15} 16$ Here, he and the movement faced fiercer opposition from organised medicine and defensive doctors. In chapter 20, he describes the existing systems to ensure physician competence ('they are not well coordinated, and don't work very well') and efforts to put together a system that is more effective, proactive, objective, fair and responsive to patient's needs. He recounts efforts to put together a National Alliance for Physician Competence, which unfortunately fell apart for reasons Leape describes. Moreover, we should probably be worrying more about the effects of widespread clinician burnout, and resulting alienation and disengagement from their practice, their patients and quality improvement activities. We suspect this exacts a far greater toll on safety overall than the few 'incompetent' physicians whom the system may fail to identify and remediate.

For all the valuable insider insights, the book is not a 'people's history' of the patient safety movement. The idea of writing 'history from below' rather than just focusing on founding fathers and generals has taken root based on the work of Howard Zinn and others. ${ }^{17} 18$ The safety movement has been both activated and propelled by tens of thousands of frontline clinicians, patients and families. ${ }^{19} 20$ They are the ones who have witnessed and experienced the dysfunctionalities, dropped balls, disrespectful treatment, unsafe workarounds, concerns being ignored and the lip service that often masquerades as 'patient safety initiatives' - in particular, the brave patients who have stepped forward to question their care and the many more who have suffered silently. To his credit, Leape has been at the forefront of advocating more respectful treatment particularly ending the abusive, demeaning, disrespectful hierarchies and behaviours that health workers often face, exemplified by the 2013 White Paper from the Lucian Leape Institute. ${ }^{21}$ Yet, we wonder whether those on the frontlines-the nurse safety managers, the medical assistants raising concerns that are dismissed, the myriad process improvement teams that often do not receive the support and resources required to achieve and sustain safer care-would recognise their efforts in this 'history-from-above' account. $^{22}$ Regardless of these omissions, Leape has provided a valuable service in making this rich history/ memoir freely available (135000 copies have already been downloaded) and in weaving together the ideas, background, recommendations and future visions for safety.

\section{WHAT HAVE WE ACCOMPLISHED AND WHERE TO GO FROM HERE?}

As collective heirs to the work Leape recounts, we must soberly assess not just the history of the field but the degree to which we have made measurable progress. From a qualitative point of view, one can point to high-profile campaigns in many countries, agencies focused on the topic, academic researchers, conferences and peer-reviewed journals, and training courses for practitioners as well as researchers. As clinicians, we also recognise that discussions of errors that occur on rounds, in safety huddles, ${ }^{23}$ and other such changes in attitudes represent massive cultural shifts in terms of the healthcare professionals involved. Given all these positive changes, one could characterise patient safety as a successful social movement within healthcare.

From a quantitative point of view, however, the field has produced relatively few clear successes. No study has shown convincing reductions in adverse events over time at a regional level. For example, there is limited evidence demonstrating significant and sustainable successes from interventions, such as the surgical checklist or the other famous safety checklist, the central line bundle. ${ }^{142425}$ Other widely promoted interventions, such as medication reconciliation, have yet to demonstrate more than small reductions in errors and no clear decrease in actual harms. ${ }^{26}$ Computerised decision support, which also held (and we would argue 
Table 1 Current challenges to improving patient safety*

\begin{tabular}{|c|c|c|}
\hline \multirow[t]{7}{*}{ Health system } & Fiscal constraints & $\begin{array}{l}\text { 'Business case for safety' not straightforward, and financial losses and care backlogs due to } \\
\text { pandemic will make safety even harder to prioritise }\end{array}$ \\
\hline & $\begin{array}{l}\text { Competing priorities to improve } \\
\text { equity and reduce health disparities }\end{array}$ & $\begin{array}{l}\text { Hard to justify investing in marginal reductions in harms in face of massive disparities in } \\
\text { life expectancy and other basic health outcomes across socioeconomic groups-disparities } \\
\text { highlighted and exacerbated by pandemic }\end{array}$ \\
\hline & Misguided metrics & Metrics often lack validity and fail to guide improvement \\
\hline & $\begin{array}{l}\text { Superficial approaches to thorny } \\
\text { problems }\end{array}$ & Many problems reflect complex interplays of deeply rooted processes and pressures ${ }^{3637}$ \\
\hline & $\begin{array}{l}\text { Expecting local solutions to unsolved } \\
\text { safety problems }\end{array}$ & $\begin{array}{l}\text { Existing evidence often furnishes no clear solutions for common problems, yet we expect } \\
\text { institutions to analyse reported incidents and develop prevention strategies }\end{array}$ \\
\hline & Inaction on better staffing & $\begin{array}{l}\text { Compelling evidence for improved nurse staffing ratios and pharmacists in clinical settings rarely } \\
\text { acted on. Leaves onus on frontline staff and safety personnel to reduce harms while staffing } \\
\text { shortfalls persist }\end{array}$ \\
\hline & Equipment design issues & $\begin{array}{l}\text { Minimal progress in applying human factors engineering to medical devices at either design or } \\
\text { procurement stages }\end{array}$ \\
\hline
\end{tabular}

\begin{tabular}{|c|c|c|}
\hline \multirow[t]{7}{*}{ Settings of care } & Persistence of fear and blame culture & Removing blame and fear is fundamental, yet still largely absent when staff are surveyed \\
\hline & $\begin{array}{l}\text { Improvement efforts consumed by } \\
\text { measurement }\end{array}$ & $\begin{array}{l}\text { Resources focused/exhausted by perpetual surveillance, effort to collect data, rather than cycles of } \\
\text { measurement and improvement }\end{array}$ \\
\hline & Overlooking qualitative inquiry & $\begin{array}{l}\text { Disproportionate emphasis on numbers rather than richer understanding afforded by qualitative } \\
\text { data and analysis }\end{array}$ \\
\hline & Electronic health records & $\begin{array}{l}\text { Disappointing benefits from computerised alerts and more complex decision support; resulting } \\
\text { alert fatigue } \\
\text { High institutional hurdles to improve existing systems, especially commercial ones } \\
\text { Clinical documentation issues and related challenges in performing manual chart reviews }\end{array}$ \\
\hline & Loop-closing failures & $\begin{array}{l}\text { Poor infrastructures, processes, and inattention to closing loops to reliably track tests results, } \\
\text { referrals, symptoms }\end{array}$ \\
\hline & $\begin{array}{l}\text { Relative neglect of cross-cutting } \\
\text { interventions (eg, teamwork, culture) }\end{array}$ & $\begin{array}{l}\text { Effective interventions }{ }^{39} \text { not disseminated because perceived as too intensive; effects on } \\
\text { patient outcomes also harder to capture, }{ }^{40} \text { so focus mostly on simpler, more marginal process } \\
\text { improvements }\end{array}$ \\
\hline & Problems in isolation & $\begin{array}{l}\text { 'Whack-a-mole' approach to numerous specific safety problems becomes exhausting and has } \\
\text { borne little fruitt }\end{array}$ \\
\hline Staff & Shortages of nurses, primary care & Pre-existing shortages substantially worsened by increased departures during pandemic \\
\hline
\end{tabular}
and other essential workers

Lack of time and support $\quad$ For both doing clinical jobs and improvement work

Burnout Burnout, demoralisation, and change fatigue are already issues pre-pandemic and even more so during/after

Little authentic interest in input from Some organisational leaders may truly appreciate input from frontlines but feel constrained by frontline staff or patients resources to do anything other than manage dialogue and appearance of action

Detachment from patients Boundaries and barriers that keep patients and staff apart rather than more deeply and personally connecting and collaborating ${ }^{4142}$

\footnotetext{
Table 1 lists some of the major challenges to progress in patient safety, organised into categories for the health system, the settings in which care occurs (hospitals, clinics, care homes, etc) and the staff who work in these settings. These challenges provide an agenda for where to direct quality and safety efforts in the future.

*Original table created by authors.
}

still holds) great promise, has delivered mostly modest improvements $^{27}$ and currently faces serious challenges related to alert fatigue from unhelpful alerting with rates of alert over-rides at times approaching $100 \%{ }^{28} 29$ Meanwhile, existing systems miss many clinically important errors. ${ }^{30}$ In short, few if any safety interventions possess the key characteristics of robust supporting evidence and widespread adoption. ${ }^{25} 31$

One might argue that the field simply needs more time to bear more fruit. Research into basic and translational research, as well as clinical research testing the fruits of these endeavours, receive orders of magnitude more funding-from public and private sources-than do efforts to improve safety or any other domain of quality. Yet, how can we justify the status quo and its implicit wait-and-see complacency especially as we live through urgent crises such as COVID-19, and the even greater threats from the climate crisis? Both of these crises already exact large tolls in morbidity and mortality and will do so even more in the years to come. Moreover, both involve huge problems of equity, the domain of quality that has historically received the least attention. Addressing these crises requires exactly the types of cultural transformations Leape suggests as our only and best hope for safe care.

After two decades of work on patient safety, we have a successful movement-no small feat. But what will it take for this movement to produce more sustained, 
robust and quantifiable progress? In our view, multiple key challenges require attention to make such progress (table 1). The extent to which these vexing challenges reflect fundamental flaws in how we have approached patient safely, versus simply representing the next set of hurdles to tackle, requires more debate, data and future personal histories such as Leape's, as the next chapter of the field unfolds.

The patient safety paradigm prioritises system change over individual behaviour improvement. Yet, examples of system change remain few and far between. Most safety interventions focus on educating staff or bombarding them with alerts, alarms and policies. We have done little to reduce the production pressures that drive care at the frontlines, nor improve nurse staffing ratios, support expanded use of clinical pharmacists, ${ }^{32} 33$ or apply design thinking and human factors engineering in robust ways (table 1). Hopefully, the next history of the field will recount how we harnessed the persistent interest in patient safety and healthcare quality more generally to successfully wrestle with these challenges and usher in substantive system changes. Achieving this agenda will require deep engagement with frontline workers, patients and families working together to learn lessons-from errors and from the history of our efforts to address them-and authentically applying them to create safer more caring systems. ${ }^{3435}$

Contributors Both authors contributed to writing and reviewing the final draft.

Funding The authors have not declared a specific grant for this research from any funding agency in the public, commercial or not-for-profit sectors.

Competing interests None declared.

Patient consent for publication Not required.

Provenance and peer review Not commissioned; internally peer reviewed.

Open access This is an open access article distributed in accordance with the Creative Commons Attribution Non Commercial (CC BY-NC 4.0) license, which permits others to distribute, remix, adapt, build upon this work noncommercially, and license their derivative works on different terms, provided the original work is properly cited, appropriate credit is given, any changes made indicated, and the use is noncommercial. See: http://creativecommons.org/licenses/by-nc/4. $0 /$.

\section{ORCID iDs}

Gordon Schiff http://orcid.org/0000-0002-2821-3994

Kaveh G Shojania http://orcid.org/0000-0002-9942-0130

\section{REFERENCES}

1 Kohn LT, Corrigan J, Donaldson MS. To err is human: building a safer health system. Washington, D.C: National Academy Press, 2000.

2 Institute of Medicine (U.S.) Committee on Quality of Health Care in America. Crossing the quality chasm: a new health system for the 21st century. Washington, D.C: National Academy Press, 2001.

3 Leape LL. Making healthcare safe: the story of the patient safety movement. Springer International Publishing.
4 Leape LL, Brennan TA, Laird N, et al. The nature of adverse events in hospitalized patients. Results of the Harvard medical practice study II. N Engl J Med 1991;324:377-84.

5 Leape LL. Error in medicine. JAMA 1994;272:1851-7.

6 Winters B, Custer J, Galvagno SM, et al. Diagnostic errors in the intensive care unit: a systematic review of autopsy studies. BMJ Qual Saf 2012;21:894-902.

7 Shojania KG, Burton EC, McDonald KM, et al. Changes in rates of autopsy-detected diagnostic errors over time: a systematic review. JAMA 2003;289:2849-56.

8 Singh H, Meyer AND, Thomas EJ. The frequency of diagnostic errors in outpatient care: estimations from three large observational studies involving us adult populations. BMJ Qual Saf 2014;23:727-31.

9 Graber ML. The incidence of diagnostic error in medicine. BMJ Qual Saf 2013;22 Suppl 2:ii21-7.

10 Dhaliwal G, Shojania KG. The data of diagnostic error: big, large and small. BMJ Qual Saf 2018;27:499-501.

11 Schiff GD. Diagnosis and diagnostic errors: time for a new paradigm. BMJ Qual Saf 2014;23:1-3.

12 Gupta A, Snyder A, Kachalia A, et al. Malpractice claims related to diagnostic errors in the hospital. BMJ Qual Saf 2017;27. doi:10.1136/bmjqs-2017-006774. [Epub ahead of print: 0908 2017].

13 Wallace E, Lowry J, Smith SM, et al. The epidemiology of malpractice claims in primary care: a systematic review. BMJ Open 2013;3. doi:10.1136/bmjopen-2013-002929. [Epub ahead of print: 1807 2013].

14 Urbach DR, Dimick JB, Haynes AB, et al. Is who's surgical safety checklist being hyped? BMJ 2019;366:14700.

15 Leape LL, Fromson JA. Problem doctors: is there a systemlevel solution? Ann Intern Med 2006;144:107-15.

16 Shojania KG, Dixon-Woods M. 'Bad apples': time to redefine as a type of systems problem? BMJ Qual Saf 2013;22:528-31.

17 Zinn H. A people's history of the United States: 1492-present. New York, NY: Harper Collins, 1980.

18 Kapilashrami A, Smith KE, Fustukian S, et al. Social movements and public health advocacy in action: the UK people's health movement. J Public Health 2016;38:413-6.

19 Bromiley $M$. The husband's story: from tragedy to learning and action. BMJ Qual Saf 2015;24:425-7.

20 Brady PW, Zix J, Brilli R, et al. Developing and evaluating the success of a family activated medical emergency team: a quality improvement report. BMJ Qual Saf 2015;24:203-11.

21 Lucian Leape Institute. Through the eyes of the workforce: creating joy, meaning, and safer health care. Boston, MA: National Patient Safety Foundation, 2013. http://www.ihi. org/resources/Pages/Publications/Through-the-Eyes-of-theWorkforce-Creating-Joy-Meaning-and-Safer-Health-Care.aspx

22 Shand J, Allwood D, Lee N, et al. Systematically capturing and acting on insights from front-line staff: the 'Bedside Learning Coordinator'. BMJ Qual Saf 2021;30:509-12.

23 Brady PW, Goldenhar LM. A qualitative study examining the influences on situation awareness and the identification, mitigation and escalation of recognised patient risk. BMJ Qual Saf 2014;23:153-61.

24 Marang-van de Mheen PJ, van Bodegom-Vos L. Meta-Analysis of the central line bundle for preventing catheter-related infections: a case study in appraising the evidence in quality improvement. BMJ Qual Saf 2016;25:118-29.

25 Shojania KG, Beyond C. Beyond CLABSI and CAUTI: broadening our vision of patient safety. BMJ Qual Saf 2020;29:361-4. 
26 Schnipper JL, Reyes Nieva H, Mallouk M, et al. Effects of a refined evidence-based toolkit and mentored implementation on medication reconciliation at 18 hospitals: results of the MARQUIS2 study. BMJ Qual Saf 2021. doi:10.1136/ bmjqs-2020-012709. [Epub ahead of print: 29 Apr 2021].

27 Kwan JL, Lo L, Ferguson J, et al. Computerised clinical decision support systems and absolute improvements in care: meta-analysis of controlled clinical trials. $B M J$ 2020;370:m3216.

28 Shah SN, Amato MG, Garlo KG, et al. Renal medicationrelated clinical decision support (CDS) alerts and overrides in the inpatient setting following implementation of a commercial electronic health record: implications for designing more effective alerts. J Am Med Inform Assoc 2021;28:1081-7.

29 Wright A, Aaron S, Seger DL, et al. Reduced effectiveness of Interruptive drug-drug interaction alerts after conversion to a commercial electronic health record. J Gen Intern Med 2018;33:1868-76.

30 Schiff GD, Amato MG, Eguale T, et al. Computerised physician order entry-related medication errors: analysis of reported errors and vulnerability testing of current systems. BMJ Qual Saf 2015;24:264-71.

31 Shojania KG, Thomas EJ. Trends in adverse events over time: why are we not improving? BMJ Qual Saf 2013;22:273-7.

32 Leape LL, Cullen DJ, Clapp MD, et al. Pharmacist participation on physician rounds and adverse drug events in the intensive care unit. JAMA 1999;282:267-70.

33 Kucukarslan SN, Peters M, Mlynarek M, et al. Pharmacists on rounding teams reduce preventable adverse drug events in hospital general medicine units. Arch Intern Med 2003;163:2014-8.

34 Donabedian A. The effectiveness of quality assurance. Int J Qual Health Care 1996;8:401-7.

35 Berwick D, Fox DM. "Evaluating the Quality of Medical Care": Donabedian's Classic Article 50 Years Later. Milbank Q 2016;94:237-41.

36 Kellogg KM, Hettinger Z, Shah M, et al. Our current approach to root cause analysis: is it contributing to our failure to improve patient safety? BMJ Qual Saf 2017;26:381-7.

37 Reed JE, Card AJ. The problem with Plan-Do-Study-Act cycles. BMJ Qual Saf 2016;25:147-52.

38 Schiff GD, Tharayil MJ. Electronic clinical documentation. In: Key advances in clinical informatics. Academic Press, 2017: 51-68.

39 Neily J, Mills PD, Young-Xu Y, et al. Association between implementation of a medical team training program and surgical mortality. JAMA 2010;304:1693-700.

40 Shojania KG, Marang-van de Mheen PJ. Identifying adverse events: reflections on an imperfect gold standard after 20 years of patient safety research. BMJ Qual Saf 2020;29:265-70.

41 Schiff GD. Crossing Boundaries-Violation or obligation? JAMA 2013;310:1233-4.

42 Schiff GD, Graber ML. 2019 John M. Eisenberg patient safety and quality awards: an interview with Gordon D. Schiff Jt Comm J Qual Saf 2020;46:371-80. doi:10.1016/j. jcjq.2020.04.008 